\title{
Growth of Vertically Aligned Carbon Nanotubes on Silicon Using a Sparked Iron-Cobalt Catalyst
}

\author{
Sirikamon Saengmee-anupharb, ${ }^{1}$ Sanitta Thongpang, ${ }^{2}$ Erwin S. P. Bertheir, ${ }^{2}$ \\ and Pisith Singjai ${ }^{1,3}$ \\ ${ }^{1}$ Department of Physics and Materials Science, Faculty of Science, Chiang Mai University, Chiang Mai 50200, Thailand \\ ${ }^{2}$ Biomedical Engineering Department, University of Wisconsin, Madison, WI 53706-1609, USA \\ ${ }^{3}$ Materials Science Research Center, Faculty of Science, Chiang Mai University, Chiang Mai 50200, Thailand
}

Correspondence should be addressed to Pisith Singjai, singjai@chiangmai.ac.th

Received 15 April 2011; Accepted 28 May 2011

Academic Editor: I. Škorvánek

Copyright (C) 2011 Sirikamon Saengmee-anupharb et al. This is an open access article distributed under the Creative Commons Attribution License, which permits unrestricted use, distribution, and reproduction in any medium, provided the original work is properly cited.

\begin{abstract}
Vertically aligned carbon nanotubes (VA-CNTs) were successfully grown on silicon substrates by atmospheric pressure chemical vapor deposition at $750^{\circ} \mathrm{C}$ using acetylene as a carbon source and Fe-Co nanoparticle thin films as a cocatalyst. Preparation of the cocatalyst was operated by an economical sparking process. A small amount of water vapor was introduced into the reactor by controlling diffusion by heated water in a flask. The CNTs were characterized by scanning electron microscopy, transmission electron microscopy, and Raman spectroscopy. The VA-CNTs were obtained only when the water vapor fraction in the introduced gas was in the range of $310-440 \mathrm{ppm}$. The length of the VA-CNTs reached $0.8 \mathrm{~mm}$ with a growth rate of $17 \mu \mathrm{m} / \mathrm{min}$. Moreover, $\mathrm{D} / \mathrm{G}$-band ratio suggests that the optimum fraction of water vapor decreases defects in CNTs.
\end{abstract}

\section{Introduction}

Carbon nanotubes (CNTs) are regarded as one of the most promising materials for various potential applications, such as electrodes for electrochemical double-layer capacitors [1$3]$, field emitters $[4,5]$ in flat panel displays, electron source in X-ray tubes [6], and nanoelectronic devices [7, 8]. Thus, numerous synthetic methods for production of CNTs such as arc discharge $[9,10]$, laser ablation [11], pyrolysis of hydrocarbon [12-14], and chemical vapor deposition (CVD) [15, 16] were developed. The CVD technique has attracted particular attention because of its ability to produce a high yield of very pure CNTs at low costs, while being easily scaled up [17].

Nevertheless, long vertically aligned CNTs remain challenging to produce. Hata and coworkers reported that the introduction of a small fraction of water into the CVD growth environment increases dramatically the achievable growth height of single-wall nanotubes (SWNTs) [18]. We believe that a simple and economical fabrication system is essential for further industrial manufacturing. In this view, we aimed at eliminating the traditional costly equipment for catalyst deposition and water vapor insertion. We used an iron-cobalt cocatalyst, prepared from a sparking process [19, 20 ] in conjunction with a diffusion-controlled water insertion method. CNTs were synthesized using CVD with acetylene as a carbon source in an argon carrier gas. The amount of vapor is essential in order to achieve high-purity and long vertically aligned CNTs [21] and the diffusion-controlled insertion allows precise control of water vapor even for very low gas flows. Nasibulin and coworkers have demonstrated the effect of $\mathrm{CO}_{2}$ and $\mathrm{H}_{2} \mathrm{O}$ vapor on the synthesis of $\mathrm{CNT}$ grown in situ using premade Co and Fe catalyst nanoparticles and particles deposited by a hot wire generator [21].

Here, we focused on an alternative way of preparing the catalyst in a cost-effective and simple manner, using a highvoltage sparking process that can produce evenly distributed 5-30 nm in diameter nanoparticles. The effect of different amount of vapor or the ratio of carbon, hydrogen, and oxygen in the synthesis process also reported in this paper. 


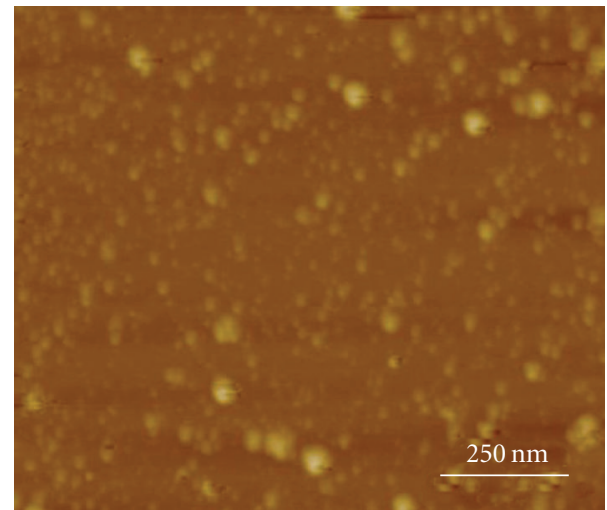

FIgURE 1: AFM image of Fe-Co nanoparticles on Si substrate obtained by sparking process at $12 \mathrm{kV}$.

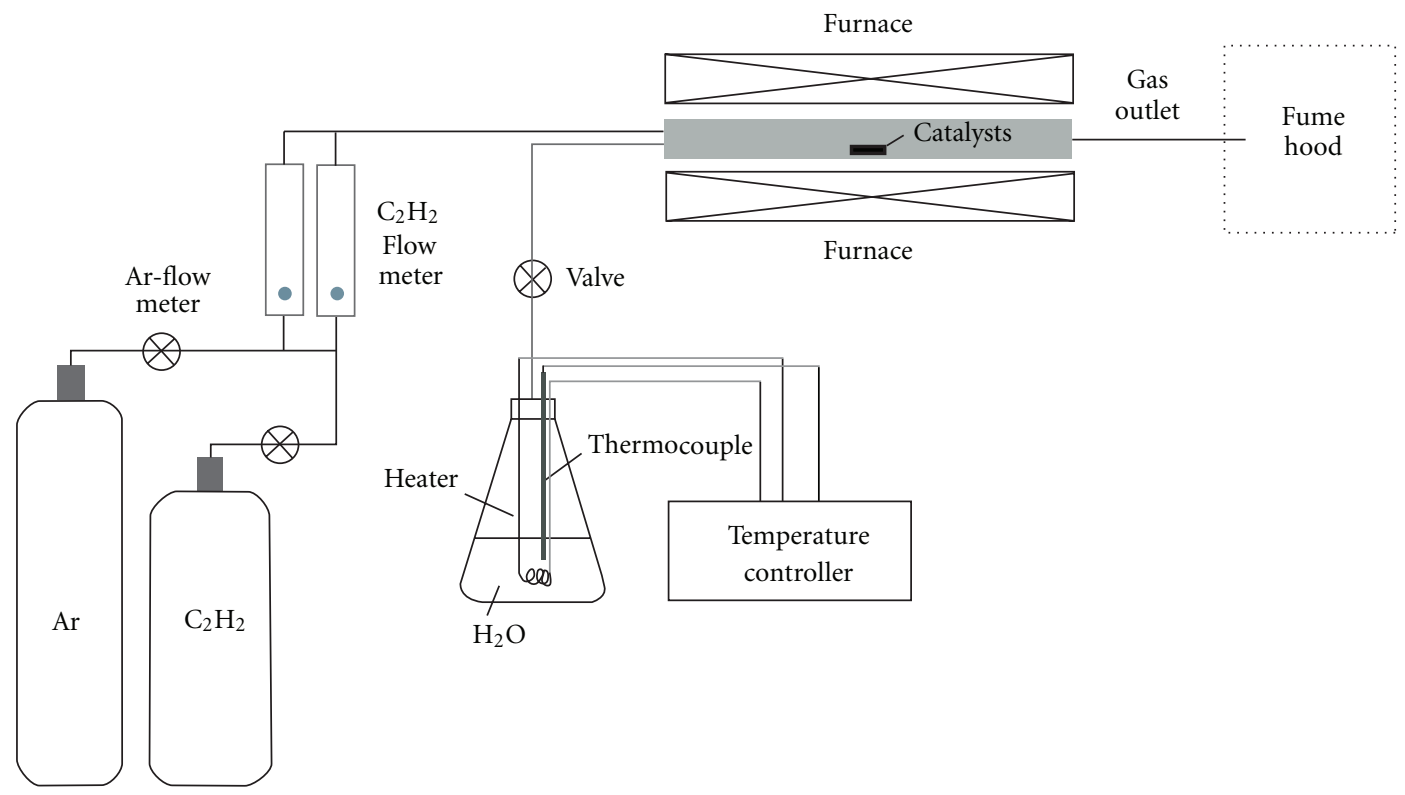

FIGURE 2: Schematic diagram of CVD apparatus.

\section{Experimental Details}

The CNTs are synthesized on a Si substrate with a Fe-Co catalyst. Si substrates are sonically cleaned in acetone ethanol and dried. The Fe-Co nanoparticles are prepared using a high-voltage sparking process. Iron wire (Advent Research Materials Ltd., $\phi 0.25 \mathrm{~mm}$, purity $99.95 \%$ ) is used for the anode tip and cobalt wire (Advent Research Materials Ltd., $\phi 0.25 \mathrm{~mm}$, purity $99.95 \%$ ) for the cathode tip. The tips are placed $1 \mathrm{~mm}$ apart and approximately $1 \mathrm{~mm}$ above the horizontally placed $5 \times 7 \mathrm{~mm}$ Si substrate (Ted Pella, Inc.) to ensure even distribution of the particles. A capacitor $(25 \mathrm{nF})$ is charged up to $12 \mathrm{kV}$ after which the voltage is applied to the tips creating a spark. Fe and Co nanoparticles are torn from the tips and deposit on the Si surface. Consequently, $\mathrm{Fe}$ and Co nanoparticles deposited onto the substrate. Figure 1 shows the typical Fe-Co nanoparticles with a diameter ranging from 6 to $59 \mathrm{~nm}$ as estimated from the AFM measure- ment. Dense and homogenous Fe/Co nanoparticle distribution is desired in order to obtain vertically aligned CNTs growing from the base.

The CVD apparatus is set up for CNTs synthesis as shown in the schematic diagram in Figure 2. The ceramic porcelain ceramic furnace tube of $4 \mathrm{~mm}$ diameter is cleaned using alcohol, and the processed Si substrate is placed at the center of the furnace. Then, the furnace is heated up to $750^{\circ} \mathrm{C}$ in Ar gas flowing at $100 \mathrm{sscm}$. When temperature is reached, acetylene is added to the gas flow at $2 \mathrm{sscm}$ and water vapor is introduced into the reactor by controlled diffusion. Using Fick's law of diffusion, the vapor flow rate was calculated to be in the range of $200-350 \mathrm{ppm}$ when the water flask is heated at $\left(30-65^{\circ} \mathrm{C}\right)$. After the growth time ( $15 \mathrm{~min}$ to $4 \mathrm{hr}$ ), the reactor was cooled to room temperature in $\mathrm{Ar}$ atmosphere and the reaction is terminated. The as-synthesized products were characterized by scanning electron microscopy (SEM, JEOL JSM-6335F), transmission 


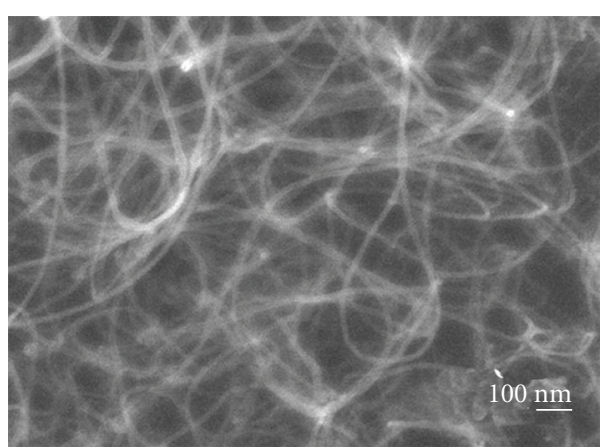

(a)

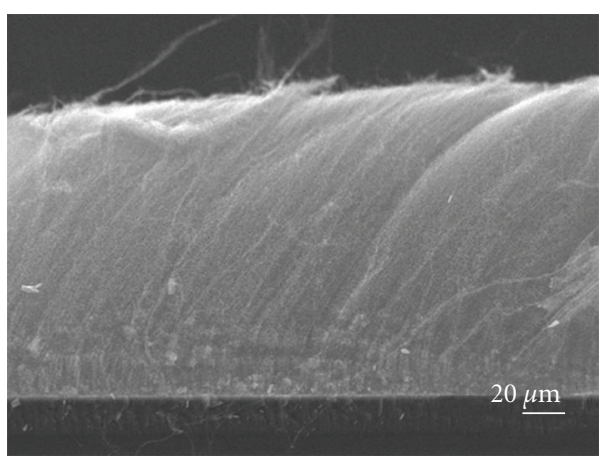

(c)

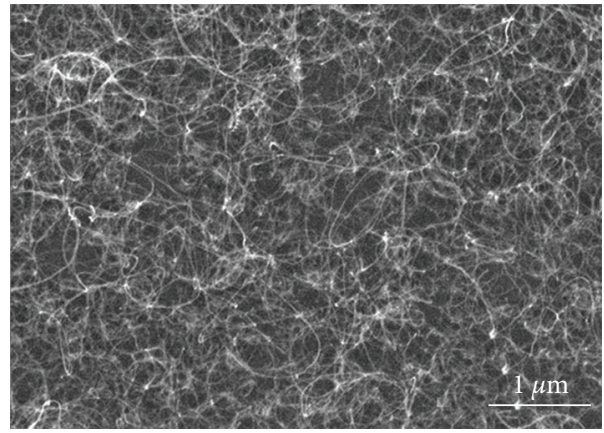

(b)

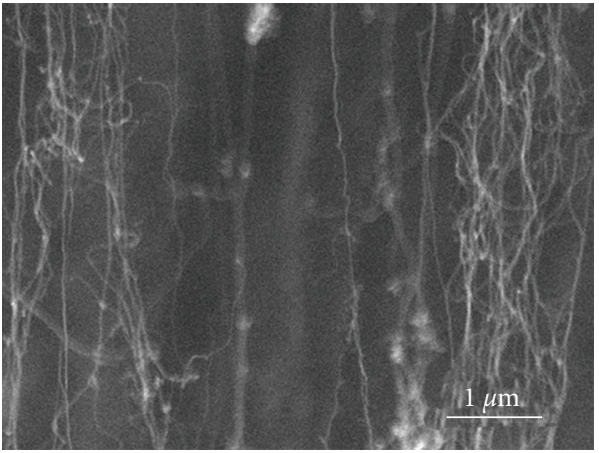

(d)

FIGURE 3: SEM images of CNTs growth on a Si substrate (a,b) under the water-vapor-free condition, (c, d) under the water-vapor assisted condition.

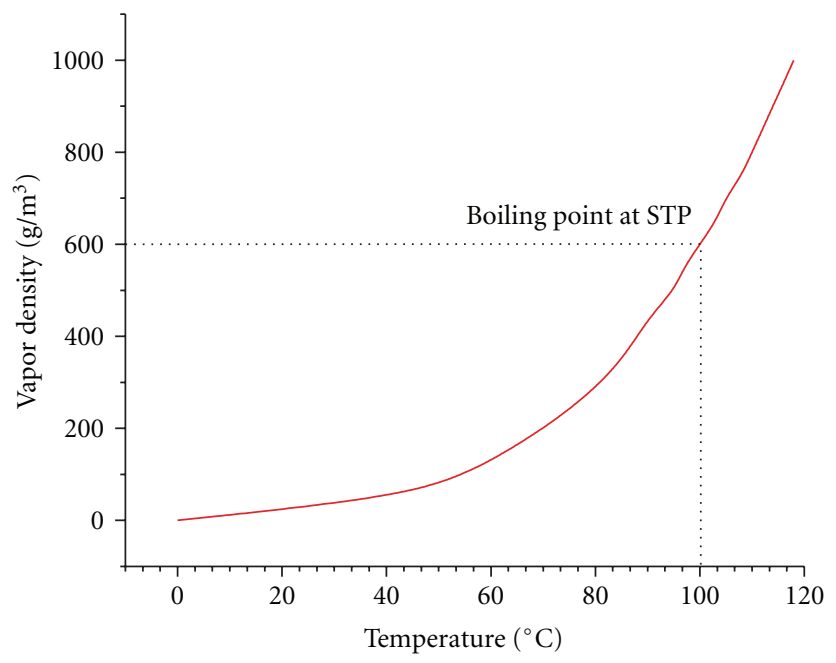

Figure 4: Empirical fit of saturated vapor density versus Celsius temperature.

electron microscopy (TEM, JEOL JEM-2010), and Raman Spectroscopy (HORIBA JOBIN YVON T64000) directly on the substrate.

\section{Results and Discussion}

Typically, a deposited film can be visually observed after 15 seconds in growth conditions once the acetylene is introduced. The carbon nanotube films are dull black in color and can be grown in the areas covered by the sparking process. Figures 3(a) and 3(b) show SEM images of the CNTs synthesized at $750^{\circ} \mathrm{C}$ with 50 to $1(100: 2 \mathrm{sccm})$ Ar to acetylene ratio in water-vapor-free condition.

On the other hand, water vapor plays a critical role in the length of vertically aligned CNT synthesis. In its absence, the CNTs curl up in bundles as shown in Figures 3(a) and 3 (b), rather than growing upwards. CNTs grow in rapid rate initially, and, because of its high density of CNTs, they 


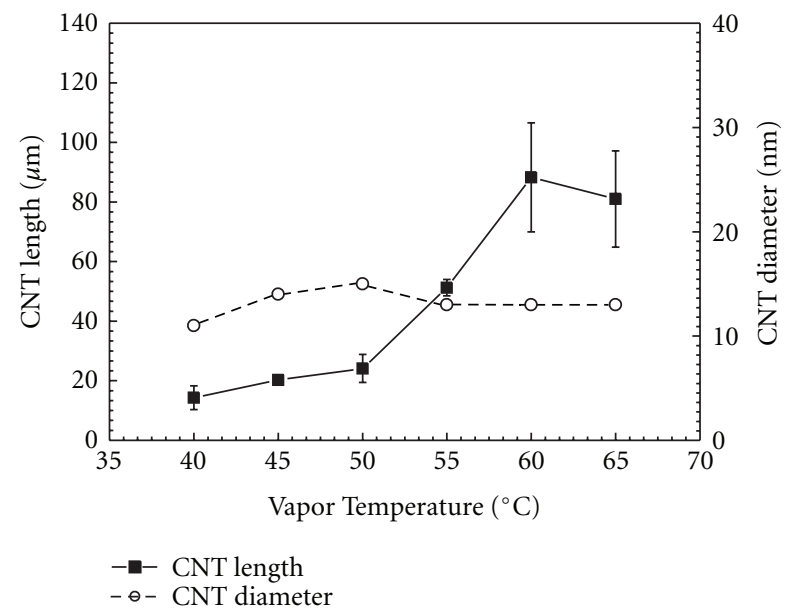

FIGURE 5: The effect of flow rate of water vapor on the diameter and length of CNTs.

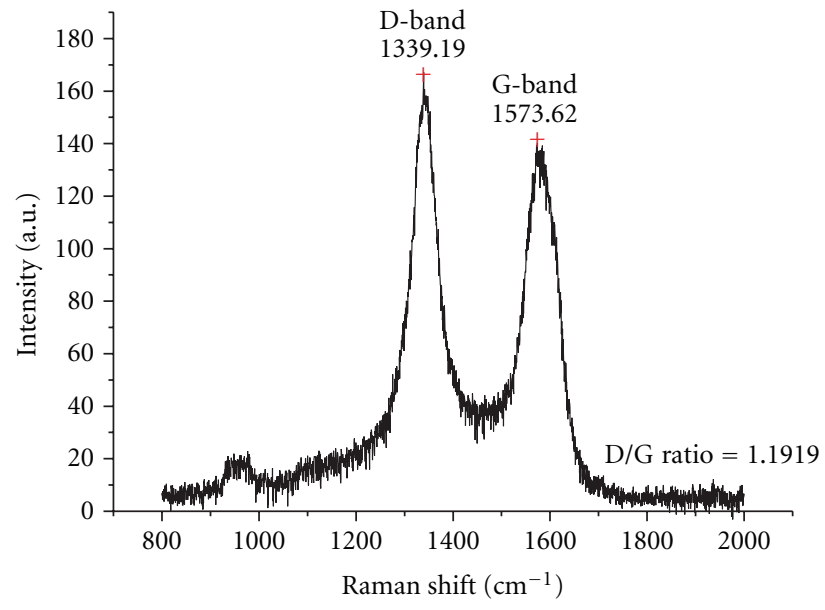

FIGURE 6: Raman spectra of the as-grown CNTs over Si substrate.

control each other to grow vertically. The evenly distributed VA-CNTs shown in Figures 3(c) and 3(d) are formed in the presence of the right amount of water vapor $(1.7 \mu \mathrm{mol} / \mathrm{min}$ in our case). We control the flux of water vapor delivered through control of the diffusive flux out of the flask. The diffusive flux $J$ is given by Fick's law of diffusion as illustrated in

$$
J=-D\left(\frac{\partial C}{\partial x}\right)
$$

where $D$ is the diffusion coefficient and $x$ is the position. In the case of a tube the flux can be expressed

$$
J=\frac{A D C_{\text {sat }}(T)}{L},
$$

with $A$, the cross section of the tube, $L$, the length of the tube from the flask outlet to the furnace, and $C_{\text {sat }}$, the saturated water vapor concentration at a temperature $T$. Therefore, the flux can be controlled via geometrical parameters, such as the length or the cross-section of the tubing, or by the absolute value of the vapor concentration in the source. The latter can be readily varied by heating the water as shown in Figure 4 .
In our system, the diffusion coefficient of water vapor is $2.5 \times 10^{-5} \mathrm{~m}^{2} / \mathrm{s}$, the length $L$ of the tube is $0.3 \mathrm{~m}$, and $C_{\text {sat }}$ for a flask heated at $45^{\circ} \mathrm{C}$ is $100 \mathrm{~g} / \mathrm{m}^{3}$. Hence, the flow of water vapor obtained from this approach is $0.9 \mu \mathrm{mol} / \mathrm{min}$. Furthermore, in the presence of water vapor, the CNT yields appear to contain less amorphous carbon potentially due to its etching by an oxidizer like oxygen (Figure 3) [22-25]. However, the high content in $\mathrm{H}$ radicals can etch the preformed CNTs [26] causing CNTs growth rate reduction. However, when growing vertical multiwalled nanotubes (MWNTs) the H-blocking effect should be lesser due to higher stability of larger tubes [26].

In contrast, the added water vapor has an insignificant effect on the nanotube diameter which result in CNT diameters ranging from 7 to $22 \mathrm{~nm}$ with an average size of approximately $13 \pm 3 \mathrm{~nm}$. We found that the optimum water vapor delivery rate for obtaining the longest CNTs is of $1.7 \mu \mathrm{mol} / \mathrm{min}(370 \mathrm{ppm})$ at $75^{\circ} \mathrm{C}$ (Figure 5). At lower delivery rates (up to $1.2 \mu \mathrm{mol} / \mathrm{min}$ or $260 \mathrm{ppm}$ ), the process yields shorter CNTs only approximately 20 um long. However, by increasing the delivery rate to more than $1.8 \mu \mathrm{mol} / \mathrm{min}$ 


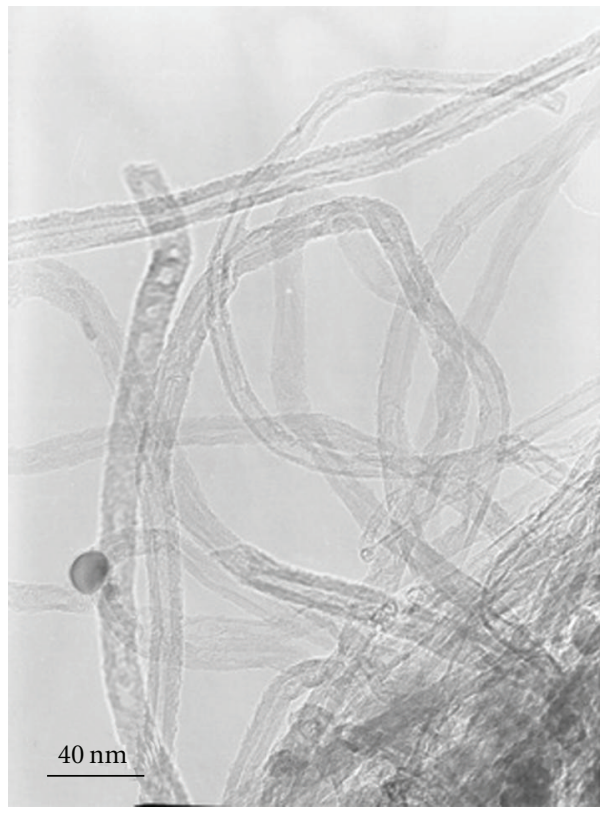

(a)

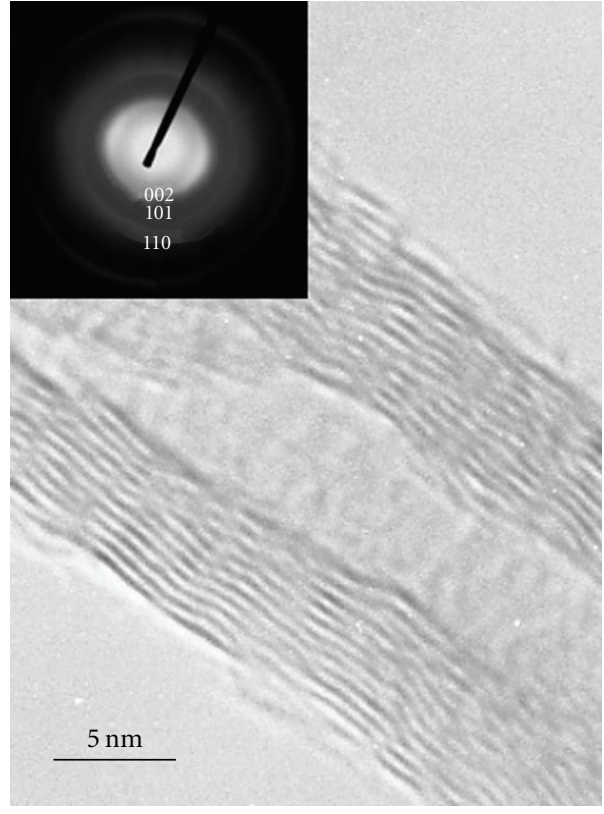

(b)

FIGURE 7: TEM image at low magnification (a) high-resolution TEM image and the associated SADP (inset image) of individual VA-CNTs (b).

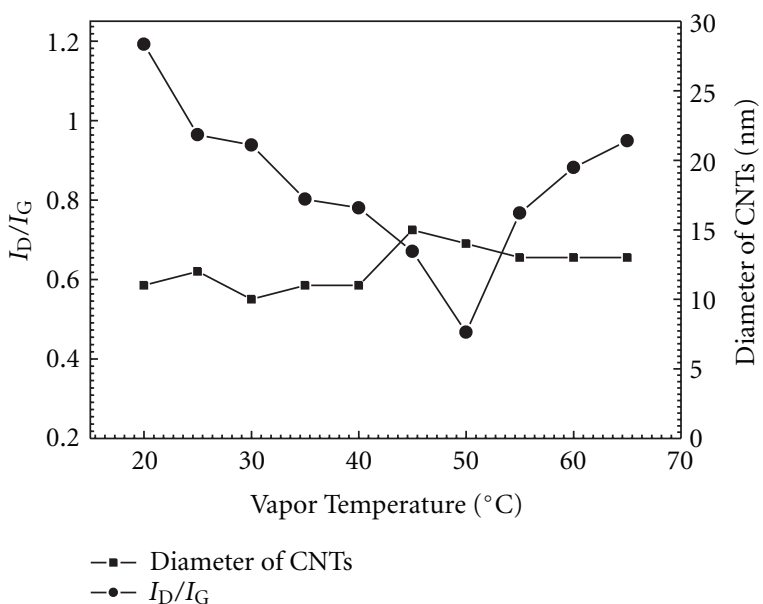

FIGURE 8: Comparison of the $I_{\mathrm{D}} / I_{\mathrm{G}}$ ratio as the degree of structural defects and the CNTs diameter of as-grown VA-CNTs which adding water vapor in difference temperature.

(400 ppm), the length of CNTs is reduced due to the cleavage effect of excessive $\mathrm{H}$ and $\mathrm{O}$ radicals. Since the flux of water vapor is central to CNT growth, we suggest an optimum ratio of water/acetylene for vertically aligned MWNT synthesis of (370/17000). This is based on our best result in which the flow rates of argon, acetylene, and water vapor are $4.5 \mathrm{mmol} / \mathrm{min}(17000 \mathrm{ppm}), 77 \mu \mathrm{mol} / \mathrm{min}$, and $1.7 \mu \mathrm{mol} /$ min $(370 \mathrm{ppm})$, respectively. Zhang and coworkers suggested that CNT synthesis in a CVD process without $\mathrm{O}_{2}$ yields no VA-SWNTs while the absence of $\mathrm{H}_{2}$ still produces VA-SWNT [25]. This supports our results demonstrating that a small amount of oxygen can promote VA-CNT growth. Hence, small amount of water vapor can increase CNT yields.
In the optimal conditions aforementioned, the fraction of water vapor and acetylene delivered to the reaction are $370 \mathrm{ppm}$ and $17,000 \mathrm{ppm}$, respectively. These values are in the same range as other reports which mention water vapor fraction in the range of 100-400 ppm and a carbon source fraction in the range of 1500-10,000 ppm, [27-29]. This also asserts the soundness of the diffusive delivery approach we employed for adding water vapor, as it provides accurate control in the small ranges flux rates involved as well as a simple electronic free method.

The peaks of the Raman spectra performed on the CNTs are centered at 1339 and $1573 \mathrm{~cm}^{-1}$ and correspond to the disorder-induced vibrational mode (D-band) and 


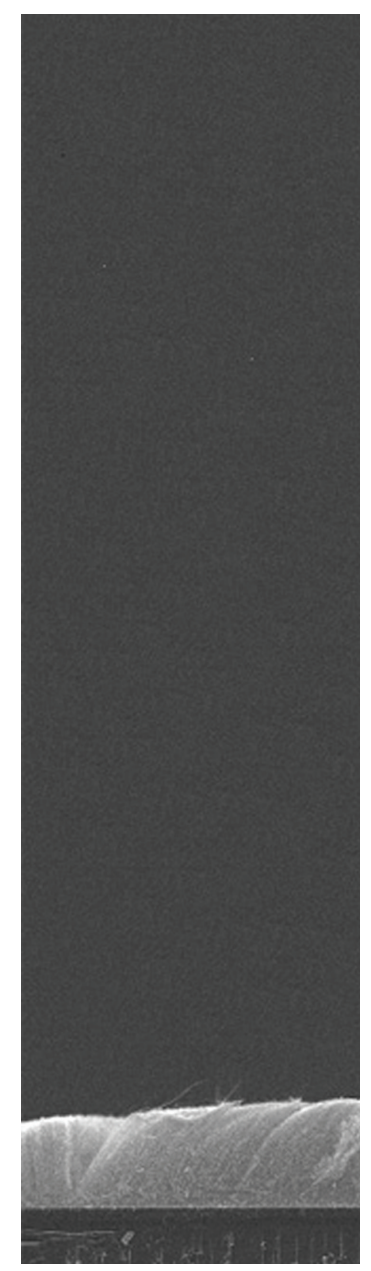

(a)

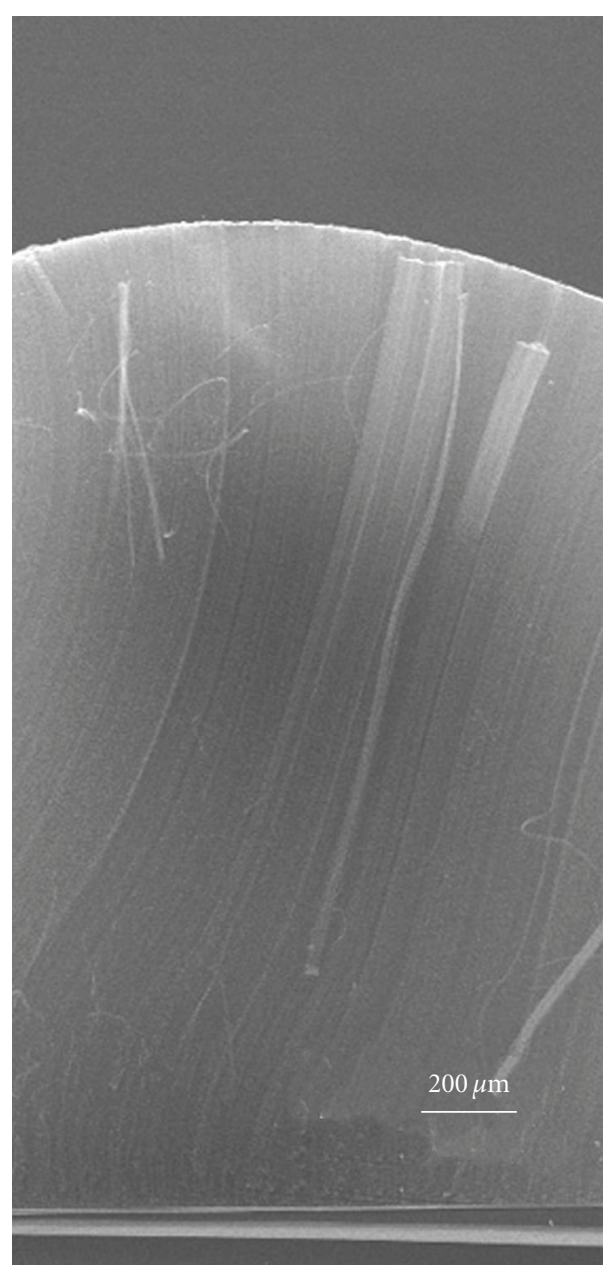

(b)

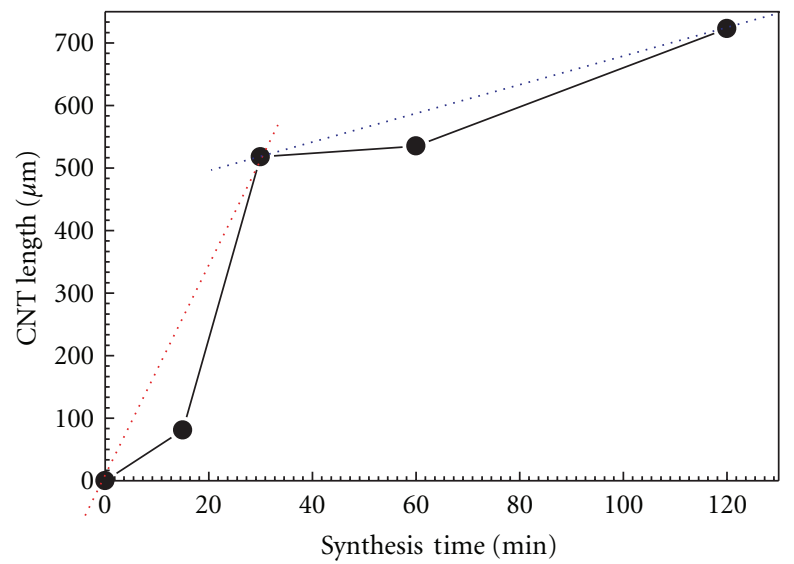

(c)

FIGURE 9: SEM images of VA-CNTs showing effect of growth of time: (a) 15 min and (b) $2 \mathrm{hr}$, (a, b) used the same scale, (c) Evolution of VA-CNTs length with time at $750^{\circ} \mathrm{C}$ with $65^{\circ} \mathrm{C}$ water vapor and $\mathrm{Ar}$ flow rates at $100 \mathrm{~mL} / \mathrm{min}$.

the in-plane carbon stretching mode (G-band), respectively (Figure 6). The D-band/G-band intensity ratio $\left(I_{\mathrm{D}} / I_{\mathrm{G}}\right)$ decreased with the addition of water vapor. This indicates that the introduction of small amounts of water vapor to the growth environment decreased defect levels in the atomic carbon structure.
Moreover, TEM images and (inset) the associate selected area electron diffraction pattern (SADP) of the individual VA-CNTs are shown in Figure 7 providing further information on the morphology and microstructure of assynthesized VA-CNTs over Fe-Co/Si catalyst. Figure 7(a) shows the uniformity of VA-CNTs without metal catalyst 
nanoparticles or amorphous carbon at lower resolution. The outer diameter of the CNT is $8-20 \mathrm{~nm}$ and inner diameter is $3-5 \mathrm{~nm}$ with 10 walls on average as presented in Figure 7(b). The fringes of graphite layers show the VA-CNT structure with less of the degree of disorder and defects. The hexagonal structure of MWNTs has been confirmed by the corresponding crystallographic (002), (101), and (110) planes.

Figure 8 shows a comparison of the $I_{\mathrm{D}} / I_{\mathrm{G}}$ ratio as the degree of structural defects and the CNTs diameter of asgrown CNTs which add water vapor in difference temperature. The result illustrated that increasing the temperature of water vapor, decrease the defect of atomic structure of CNTs.

Our best condition for CNT synthesis, water heated at $65^{\circ} \mathrm{C}(444 \mathrm{ppm})$, was found to be nanotubes grew rapidly at the early stage and then slowed down to reach their saturation stage. The relationship between CNTs length and synthesis time is illustrated in Figure 9 showing rapid growth of $17.3 \mu \mathrm{m} / \mathrm{min}$ in the second stage from 20th to 40 th minute, then the growth rate reduces to $2.3 \mu \mathrm{m} / \mathrm{min}$. From this relationship, only $30 \mathrm{~min}$ would be adequate to grow VACNTs up to $500 \mu \mathrm{m}$.

\section{Conclusions}

VA-CNTs were successfully synthesized using Fe/Co catalyst deposited by a cost-effective high-voltage sparking process. Growth was effectuated using CVD with acetylene as a carbon source with a small amount of water vapor addition to the growth environment through a simple diffusion process. The vapor-assisted conditions provided increased quantity and quality of CNTs. Furthermore, the D-band/G-band ratio signifies that the defect of atomic carbon structure was decreased. These results demonstrate that water vapor is essential for long VA-CNTs synthesis.

\section{Acknowledgment}

The authors thank the National Research University Project under Thailand's Office of the Commission on Higher Education (CHE) for financial support.

\section{References}

[1] C. Emmenegger, P. Mauron, P. Sudan, P. Wenger, V. Hermann, R. Gallay et al., "Investigation of electrochemical doublelayer capacitors electrodes based on carbon nanotubes and activated carbon materials," Journal of Power Sources, vol. 124, no. 1, pp. 321-329, 2003.

[2] K. H. An, W. S. Kim, Y. S. Park et al., "Electrochemical properties of high-power supercapacitors using single-walled carbon nanotube electrodes," Advanced Funtional Materials, vol. 11, no. 5, pp. 387-392, 2001.

[3] J. H. Chen, W. Z. Li, D. Z. Wang, S. X. Yang, J. G. Wen, and Z. F. Ren, "Electrochemical characterization of carbon nanotubes as electrode in electrochemical double-layer capacitors," Carbon, vol. 40, no. 8, pp. 1193-1197, 2002.

[4] L. Nilsson, O. Groening, C. Emmenegger et al., "Scanning field emission from patterned carbon nanotube films," Applied Physics Letters, vol. 76, no. 15, pp. 2071-2073, 2000.
[5] J. M. Bonard, H. Kind, T. Stöckli, and L. O. Nilsson, "Field emission from carbon nanotubes: the first five years," SolidState Electronics, vol. 45, no. 6, pp. 893-914, 2001.

[6] H. Sugie, M. Tanemura, V. Filip, K. Iwata, K. Takahashi, and F. Okuyama, "Carbon nanotubes as electron source in an X-ray tube," Applied Physics Letters, vol. 78, no. 17, pp. 2578-2580, 2001.

[7] K. Tsukagoshi, N. Yoneya, S. Uryu et al., "Carbon nanotube devices for nanoelectronics," Physica B, vol. 323, no. 1-4, pp. 107-114, 2002.

[8] F. Léonard and J. Tersoff, "Multiple functionality in nanotube transistors," Physical Review Letters, vol. 88, no. 25 I, pp. 2583021-2583024, 2002.

[9] Y. Saito, "Carbon nanotubes produced by arc discharge," New Diamond and Frontier Carbon Technology, vol. 9, no. 1, pp. 130, 1999.

[10] D. S. Bethune, C. H. Kiang, M. S. De Vries et al., "Cobaltcatalysed growth of carbon nanotubes with single-atomiclayer walls," Nature, vol. 363, no. 6430, pp. 605-607, 1993.

[11] A. Thess, R. Lee, P. Nikolaev et al., "Crystalline ropes of metallic carbon nanotubes," Science, vol. 273, no. 5274, pp. 483-487, 1996.

[12] H. M. Cheng, F. Li, G. Su et al., "Large-scale and low-cost synthesis of single-walled carbon nanotubes by the catalytic pyrolysis of hydrocarbons," Applied Physics Letters, vol. 72, no. 25, pp. 3282-3284, 1998.

[13] M. Terrones, N. Grobert, J. Olivares et al., "Controlled production of aligned-nanotube bundles," Nature, vol. 388, no. 6637, pp. 52-55, 1997.

[14] R. Sen, A. Govindaraj, and C. N. R. Rao, "Carbon nanotubes by the metallocene route," Chemical Physics Letters, vol. 267, no. 3-4, pp. 276-280, 1997.

[15] W. Z. Li, S. S. Xie, L. X. Qian et al., "Large-scale synthesis of aligned carbon nanotubes," Science, vol. 274, no. 5293, pp. 1701-1703, 1996.

[16] S. Fan, M. G. Chapline, N. R. Franklin, T. W. Tombler, A. M. Cassell, and H. Dai, "Self-oriented regular arrays of carbon nanotubes and their field emission properties," Science, vol. 283, no. 5401, pp. 512-514, 1999.

[17] P. Singjai, S. Changsarn, and S. Thongtem, "Electrical resistivity of bulk multi-walled carbon nanotubes synthesized by an infusion chemical vapor deposition method," Materials Science and Engineering A, vol. 443, no. 1-2, pp. 42-46, 2007.

[18] K. Hata, D. N. Futaba, K. Mizuno, T. Namai, M. Yumura, and S. Iijima, "Water-assisted highly efficient synthesis of impurity-free single-walled carbon nanotubes," Science, vol. 306, no. 5700, pp. 1362-1364, 2004.

[19] T. Kumpika, W. Thongsuwan, and P. Singjai, "Atomic force microscopy imaging of $\mathrm{ZnO}$ nanodots deposited on quartz by sparking off different tip shapes," Surface and Interface Analysis, vol. 39, no. 1, pp. 58-63, 2007.

[20] T. Kumpika, W. Thongsuwan, and P. Singjai, "Optical and electrical properties of $\mathrm{ZnO}$ nanoparticle thin films deposited on quartz by sparking process," Thin Solid Films, vol. 516, no. 16, pp. 5640-5644, 2007.

[21] M. Jung, K. Yong Eun, J. K. Lee, Y. J. Baik, K. R. Lee, and J. Wan Park, "Growth of carbon nanotubes by chemical vapor deposition," Diamond and Related Materials, vol. 10, no. 3-7, pp. 1235-1240, 2001.

[22] S. Inoue, T. Nakajima, and Y. Kikuchi, "Synthesis of single-wall carbon nanotubes from alcohol using $\mathrm{Fe} / \mathrm{Co}, \mathrm{Mo} / \mathrm{Co}, \mathrm{Rh} / \mathrm{Pd}$ catalysts," Chemical Physics Letters, vol. 406, no. 1-3, pp. 184187, 2005.

[23] H. Kathyayini, N. Nagaraju, A. Fonseca, and J. B. Nagy, "Catalytic activity of $\mathrm{Fe}$, $\mathrm{Co}$ and $\mathrm{Fe} / \mathrm{Co}$ supported on $\mathrm{Ca}$ and $\mathrm{Mg}$ 
oxides, hydroxides and carbonates in the synthesis of carbon nanotubes," Journal of Molecular Catalysis A, vol. 223, no. 1-2, pp. 129-136, 2004.

[24] K. Dasgupta, R. Venugopalan, and D. Sathiyamoorthy, "The production of high purity carbon nanotubes with high yield using cobalt formate catalyst on carbon black," Materials Letters, vol. 61, no. 23-24, pp. 4496-4499, 2007.

[25] M. Jung, K. Yong Eun, J. K. Lee, Y. J. Baik, K. R. Lee, and J. Wan Park, "Growth of carbon nanotubes by chemical vapor deposition," Diamond and Related Materials, vol. 10, no. 3-7, pp. 1235-1240, 2001.

[26] A. G. Nasibulin, D. P. Brown, P. Queipo, D. Gonzalez, H. Jiang, and E. I. Kauppinen, "An essential role of $\mathrm{CO} 2$ and $\mathrm{H} 2 \mathrm{O}$ during single-walled CNT synthesis from carbon monoxide," Chemical Physics Letters, vol. 417, no. 1-3, pp. 179-184, 2005.

[27] D. N. Futaba, K. Hata, T. Yamada, K. Mizuno, M. Yumura, and S. Iijima, "Kinetics of water-assisted single-walled carbon nanotube synthesis revealed by a time-evolution analysis," Physical Review Letters, vol. 95, no. 5, Article ID 056104, pp. $1-4,2005$.

[28] G. Zhang, D. Mann, L. Zhang et al., "Ultra-high-yield growth of vertical single-walled carbon nanotubes: hidden roles of hydrogen and oxygen," Proceedings of the National Academy of Sciences of the United States of America, vol. 102, no. 45, pp. 16141-16145, 2005.

[29] "Carbon nanotubes functionalized with fullerenes," Patent No.2007/057501, 2007. 

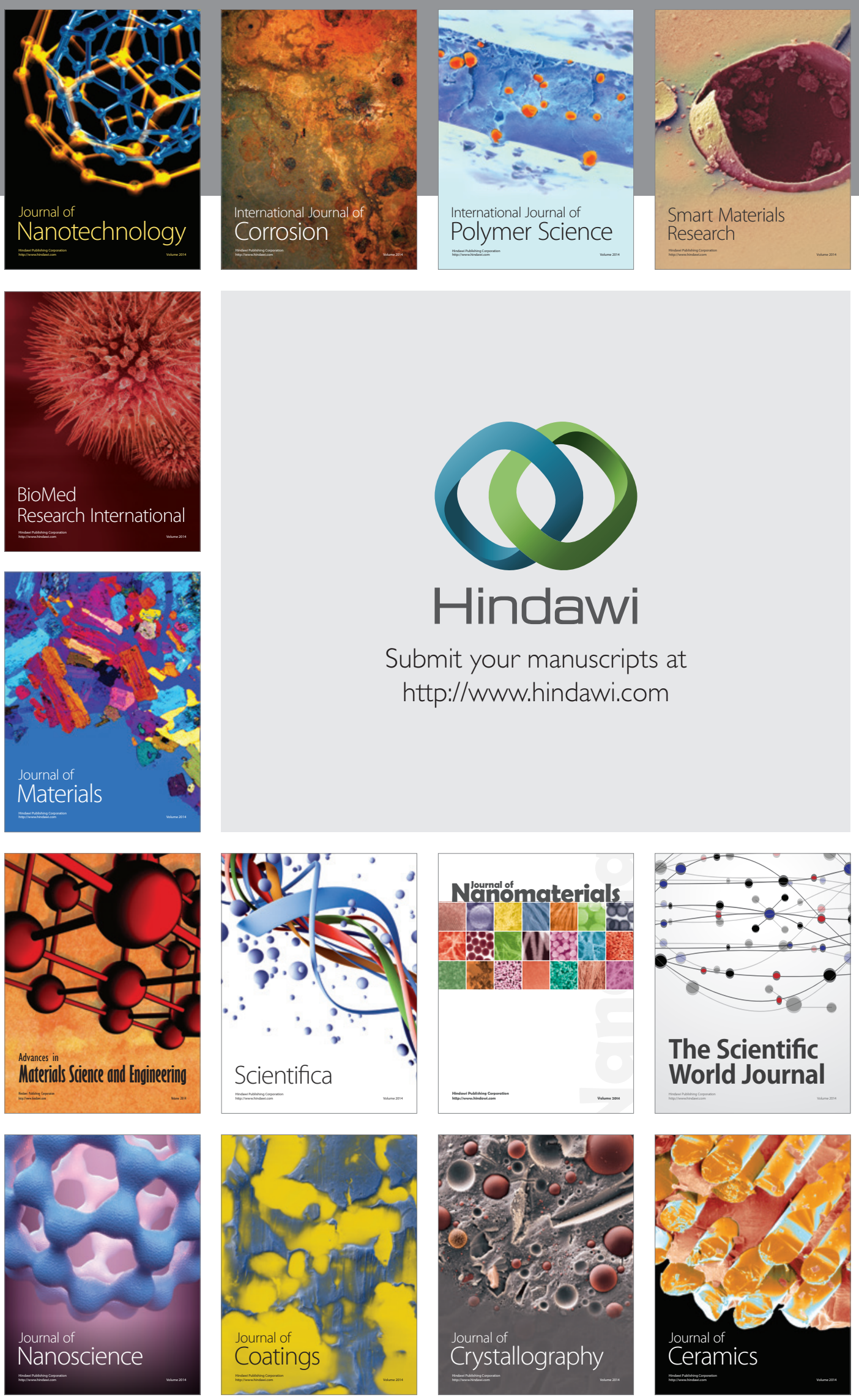

The Scientific World Journal

Submit your manuscripts at

http://www.hindawi.com

\section{World Journal}

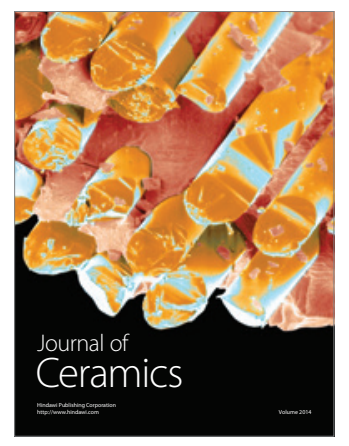

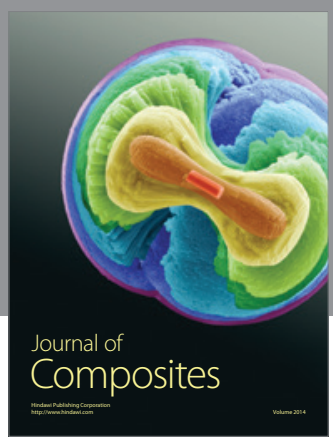
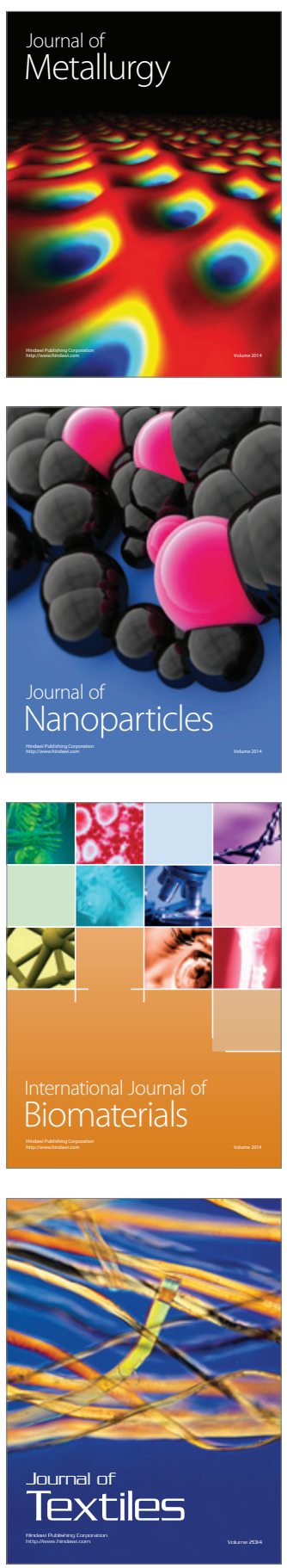